\title{
AVALIAÇÃO DA PERCEPÇÃO DA INCIDÊNCIA DE AGROTÓXICOS E SEUS POSSÍVEIS DANOS GENÉTICOS
}

\author{
EVALUATION OF THE PERCEPTION OF THE INCIDENCE OF PESTICIDES \\ AND THEIR POSSIBLE GENETIC DAMAGE
}

\author{
Lorhayne Cristina Barbosa de Souza ${ }^{1}$ \\ Luana Cristina Chaves Calili2 \\ Jeannelly Mara Perreira Araújo ${ }^{3}$ \\ Tais da Silva Tosate ${ }^{4}$ \\ Hayane Ramos Sabino 5 \\ Douglas Santiago Menezes 6 \\ Mikaely Botelho dos Reis ${ }^{7}$ \\ Vilnara Domingos Marcos 8 \\ Nathane Silva Resende9 \\ Arilton Januário Bacelar Júnior ${ }^{10}$
}

RESUMO: No Brasil tem-se um dos maiores índices de ingestão residual de agrotóxicos do mundo, em virtude principalmente do seu uso em grandes quantidades em produtos de origem vegetal. Diante disso, o fato tem se tornado uma preocupação constante e foco de diversos estudos sobre seus efeitos na saúde dos indivíduos a curto, médio e longo prazo. O presente estudo tem como objetivo discorrer os efeitos dos agrotóxicos sobre o organismo, dando ênfase na sua caraterística genotóxica, utilizando informações da literatura para descrever os efeitos adversos causados à saúde humana, diversos estudos

\footnotetext{
${ }^{1}$ Graduação em Biomedicina na Faculdade Única -Ipatinga-MG

${ }^{2}$ Graduação em Biomedicina na Faculdade Única -Ipatinga-MG

${ }^{3}$ Graduação em Biomedicina na Faculdade Única -Ipatinga-MG

${ }^{4}$ Graduação em Biomedicina na Faculdade Única -Ipatinga-MG

${ }^{5}$ Graduação em Biomedicina na Faculdade Única -Ipatinga-MG

${ }^{6}$ Graduação em Biomedicina na Faculdade Única -Ipatinga-MG

${ }^{7}$ Graduação em Biomedicina na Faculdade Única -Ipatinga-MG

${ }^{8}$ Graduação em Biomedicina na Faculdade Única -Ipatinga-MG

${ }^{9}$ Graduação em Biomedicina na Faculdade Única -Ipatinga-MG

${ }^{10}$ Graduação em Farmácia-Bioquímica pela Universidade de Marília e graduação em DIREITO pela Universidade de Marília. Atualmente é professor da Faculdade Única de Ipatinga na Graduação e Pós Graduação, Ex Coordenador do núcleo de pós graduação da Universidade Presidente Antônio Carlos que consta um portifólio de 31 cursos, EX-Presidente da CIPA da Universidade Presidente Antônio Carlos, coordenador pós- graduação farmacologia e toxicologia da Universidade Presidente Antônio Carlos, coordenador do Curso de Análises Clínicas Universidade Presidente Antônio Carlos e coordenador do curso de Farmácia da Faculdade Únicade Ipatinga. Tem experiência na área Farmacêutica e Análises Clínicas e Jurídica, Doutorando em Ciêcias Jurídicas e Sociais. Mestre em Energia Nuclear e suas Aplicações pelo Instituto de Pesquisa Nuclear IPEN-USP. Especialista em Direito Público, Especialista em Direito Educacional, Especialista em Gestão de Resíduos do Serviço de Saúde, Especialista em Doenças infecto-parasitárias, MBA em Gestão Educacional; Especialista em Análises Clínicas. Ex - Membro da Comissão de Ética do Conselho Regional de Farmácia e Membro da Comissão de Ensino do Conselho Regional de Farmácia de Minas Gerais. Atualmente é professor dos cursos de Biomedicina, Farmácia, Psicologia,Enfermagem e odontologia. ministra os conteúdos de Ciências política, Farmacologia, Psicofarmacologia, Imunologia Básica, Imunologia Clínica, Parasitologiae Microbiologia. Participou da capacitação para os Ítens do Banco Nacional de Ítens(BNI-INEP). Membro da CPA FADIPA.
} 
associam o aparecimento de danos genéticos ao consumo de agrotóxicos, bem como o aparecimento de doenças não crônicas, como problemas neurológicos, dificuldade respiratória, irritação de pele,manifestações gastrointestinais, alterações no sistema reprodutor masculino e feminino, além de cânceres no cérebro, mama, esôfago, na pele, sistema digestivo e de reprodução. $\mathrm{O}$ estudo reforça a necessidade de mais pesquisas sobre o tema, com o intuito de elucidar de forma clara os reais danos à saúde, principalmente no que diz respeito ao aspecto genético. A dificuldade de associar o aparecimento dessa mutação à somente um agente ativo parece ser o principal empecilho para o progresso nos estudos, além disso, os estudos devem levar em consideração o aspecto acumulativo dessas substâncias no organismo humano.

Palavra Chave: Agrotóxico. Genotoxidade. Resíduos em Alimentos. Danos genéticos.

ABSTRACT: Brazil has one of the highest levels of pesticide residual ingestion in the world, mainly due to its use in large quantities in products of plant origin. Therefore, the fact has become a constant concern and focus of several studies on its effects on the health of individuals in the short, medium and long term. This study aims to discuss the effects of pesticides on the body, emphasizing their genotoxic characteristic, using information from the literature to describe the adverse effects caused to human health, several studies associate the appearance of genetic damage to the consumption of pesticides, as well. such as the appearance of non-chronic diseases. Such as neurological problems, breathing difficulties, skin irritation, gastrointestinal manifestations, alterations in the male and female reproductive system, as well as cancers such as the brain, breast, esophagus, skin and digestive and reproduction systems. The study reinforces the need for more research on the subject, in order to clearly elucidate the real damage to health, especially with regard to the genetic aspect. The difficulty of associating the appearance of this mutation with only one active agent seems to be the main obstacle to progress in studies, in addition, studies must take into account the cumulative aspect of these substances in the human body.

Keyword: Pesticides. Genotoxicity. Food residues. Genetic damage.

\section{INTRODUÇÃO}

Os agrotóxicos possuem um papel muito importante na produção agrícola, sendo responsáveis pelo controle de pestes e doenças, além de colaborarem no aumento da produtividade. Apesar da grande importância para a produção agrícola, os agrotóxicos podem causar danos à saúde e ao meio ambiente. ${ }^{\mathrm{I}}$

A agricultura no Brasil se desenvolveu ao longo dos anos e hoje é uma das atividades mais importantes dentro do país, sendo considerado um dos maiores produtores agrícolas do planeta, ${ }^{2}$ diante disso, o consumo de agrotóxico aumentou rapidamente, 
levando o país a se tornar um dos maiores consumidores de agrotóxicos do mundo, ${ }^{3}$ utilizando cerca de 900 milhões de litros em $2017 .{ }^{4}$

A presença de resíduos de agrotóxicos nos alimentos tornou-se a principal preocupação da Agência Nacional de Vigilância Sanitária (ANVISA), diante disso, em 200I foi criado o Programa de Análise de Resíduos de Agrotóxicos em Alimentos (PARA), e em 2003 foi instituída com a Resolução DC/ANVISA no ${ }_{\text {II9. }}^{5}$

Os resíduos de agrotóxico podem causar mutações genéticas. ${ }^{5}$ As mutações ocorrem durante a replicação e reparo do DNA, sendo a maioria, de forma espontânea, porém, estudos provaram que alguns tipos podem ser induzidos por agentes químicos, como por exemplo, os agrotóxicos. Tais mutações já foram associadas à diversas doenças não crônicas, como o câncer. ${ }^{6}$ Além das mutações, a intoxicação crônica pode causar infertilidade, malformação, aborto, infertilidade, neurotoxidade, desequilíbrio hormonal, e causar danos ao sistema imunológico. ${ }^{8}$

\section{METODOLOGIA}

O presente artigo foi realizado a partir de uma revisão sistemática de artigos e revistas publicados entre o ano de 2005 e 2020 que se trata de danos genéticos causados pela incidência de agrotóxicos em alimentos. Realizou-se uma busca virtual desses artigos nos bancos de dados da Scientific Eletronic Library Online (SCIELO), Science Direct, Biblioteca Virtual de Saúde (BVS), PubMed e o Google Acadêmico. Descritores e/ou palavras chave, na língua portuguesa, permearam as buscas, sendo os seguintes: "agrotóxico", "uso de agrotóxicos no Brasil”, "genotoxicidade" e "resíduos de agrotóxicos em alimentos". Os critérios para inclusão do artigo na revisão bibliográfica do presente artigo foram: data de publicação entre 2005 e 2020, tratar-se de um cenário brasileiro e disponibilidade integral do artigo online. Após a seleção inicial dos artigos, foi realizado o refino e escolha final desses.

\section{DISCUSSÃO}

\section{I Consumo de agrotóxico no Brasil}

Em 2008 o Brasil atingiu o primeiro lugar no ranking de consumo de agrotóxicos e o mantém até os dias atuais. ${ }^{8}$ Entre as áreas cultivadas no Brasil, destacam-se como 
maiores consumidores dessas substâncias os estados de Mato Grosso, Rio grande do Sul e Paraná.

A atual lei de Agrotóxico no 7.802, que é utilizada no Brasil, foi feita em 1989. Foi considerada uma das melhores leis mundiais para esse segmento, por abranger desde o processo de produção, ao tipo de embalagem, registro, rótulo, entre outros. Porém por não ter passado por atualização até os dias de hoje, não conseguiu acompanhar a modernização da agricultura e seu volume, perdendo assim parte de sua eficácia. ${ }^{\text {Io }}$

O limite máximo de resíduos (LMR) é uma base agronômica sobre a quantidade que se espera que permaneça no alimento para sua comercialização, sem que prejudique o ambiente ou saúde humana, esse valor varia de acordo com cada pesticida e está descrito no rótulo de cada um. Caso esse valor exceda, ou seja, encontrada alguma substância não permitida pelo órgão fiscalizador, deve-se realizar uma nova avaliação e averiguar se existe risco à saúde. ${ }^{\text {io }}$

O PARA desde sua criação e instituição em 200I, vem monitorando os níveis de agrotóxicos presentes nos alimentos que serão consumidos pelos brasileiros. Em uma pesquisa realizada pelo órgão levando em consideração os anos entre 2008 a 2018, os resultados revelam que, mais do que a utilização de agrotóxicos superior ao nível permitido, agentes tóxicos sem autorização e/ou com restrições e exclusos permanecem sendo usados no campo, acarretando riscos aos trabalhadores e aos consumidores devido ao seu potencial tóxico. ${ }^{\text {II }}$

\subsection{Malefícios do consumo de alimentos com resíduos de agrotóxicos}

No Brasil, o uso em larga escala de agrotóxicos pode causar diversos prejuízos, como deterioração do meio ambiente, intoxicação de trabalhadores e consumidores em geral. A intoxicação aguda afeta principalmente a exposição ocupacional das pessoas, enquanto a crônica é causada por alimentos em baixa dosagem e múltiplas exposições a pesticidas (resíduos de inseticidas) no meio ambiente. Esse efeito pode ocorrer muito depois da descoberta, por isso é difícil correlacionar com esse agente. Quadro i: traz uma listagem com ingredientes ativos presentes nos agrotóxicos e seu potencial risco à saúde humana e de animais. ${ }^{12}$ 
QUADRO r: Princípio ativo e consequências.

\begin{tabular}{|c|c|}
\hline Prin & Consequências \\
\hline letrina & $\begin{array}{l}\text { É tóxica para embriões de ratos, incluindo a perda pós-implantação dos fetos } \\
\text { e más-formações viscerais; em linfócitos humanos foram observadas } \\
\text { aberrações cromossômicas e trocas de cromátides irmãs; induziu a promoção } \\
\text { de tumores em camundongos. }\end{array}$ \\
\hline Epo & $\begin{array}{l}\text { Interfere com a produção dos hormônios sexual feminino e masculina, } \\
\text { como mostrada em estudos utilizando sistemas in vitro de linhagens } \\
\text { celulares humanas. }\end{array}$ \\
\hline & oras. \\
\hline Pro & $\begin{array}{l}\text { É um desregulador endócrino de diferentes eixos, diminuindo a produção e } \\
\text { síntese de } \\
\text { Hormônios corticosteroides e sexuais masculinos e femininos e } \\
\text { prejudicando diversas } \\
\text { Funções fisiológicas fundamentais à vida, como a fertilidade masculina, o } \\
\text { metabolismo de nutrientes e a regulação do sistema imunológico. }\end{array}$ \\
\hline $\mathrm{Me}$ & $\begin{array}{l}\text { Efeito imunossupressor, diminui ainda a proliferação dos linfócitos } \mathrm{T} \text { do } \\
\text { timo e a } \\
\text { Capacidade de formar anticorpos. }\end{array}$ \\
\hline Endosulfan & $\begin{array}{l}\text { Pode afetar o sistema endócrino e o metabolismo orgânico, através de sua } \\
\text { atividade nas glândulas hipófise, tireoide, suprarrenais, mamas, ovários e } \\
\text { testículos, provocando efeitos no metabolismo do organismo e alterando a } \\
\text { produção de hormônios, entre outros, do crescimento (GH), prolactina } \\
\text { (PRL), adrenocorticotrófico (ACTH), estimulante da tireoide (TSH), } \\
\left.\text { folículo estimulante (FSH), luteinizante ( } \mathrm{LH} \text { ), triiodotironina ( } \mathrm{T}_{3}\right) \text {, } \\
\text { tiroxina ( } 44 \text { ), hormônios sexuais; O endosulfan e seus isômeros } \alpha \text { e } \beta \\
\text { induziram a proliferação, in vitro, de células de câncer de mama humanas - } \\
\text { MCF-7 }\end{array}$ \\
\hline Parationa & É um desregulador endócrino, uma vez que induz a hiperglicemia e a \\
\hline
\end{tabular}


hipoinsulinemia em ratos.

Fonte: Carneiro et al., (2015)

Apesar da existência de provas consistentes que relacionam o uso de agrotóxicos à danos à saúde na literatura, a grande parte das pesquisas apontam o aparecimento de danos em animais ou estudos in vitro, além disso associam os estudos a exposição de somente a um único agente atuante. A forma como esses experimentos são conduzidos dificultam o entendimento dos verdadeiros danos à saúde, já que na prática esse tipo de situação não acontece e os indivíduos ingerem mais de um agente químico ativo nos alimentos, quando os mesmos são cultivados com agrotóxicos ${ }^{\mathrm{I2}}$. A avaliação de resíduos de agrotóxicos é muito importante, que pode ser usado em programas de avaliação do governo e pesquisa acadêmica, projetado para proteger a saúde e o meio ambiente local. Da mesma forma, existem poucos dados sobre envenenamento por pesticidas, provavelmente porque não possuem um sistema de inspeção adequado, especialmente para identificar pesticidas relacionados a intoxicações agudas e crônicas ${ }^{13}$.

Várias substâncias químicas constituem a composição de um alimento, algumas são fundamentais para o controle da saúde humana, como vitaminas e proteínas, outras podem ser potencialmente tóxicos, como resíduos de pesticidas e metais pesados. A contaminação do alimento por substâncias tóxicas podem ocorrer tanto na produção quanto no transporte e armazenamento, e se consumido, o excesso dessas substâncias pode significar um risco considerável à saúde do consumidor, pois a ingestão de um alimento contaminado acaba sendo uma rota primária de exposição para a maioria desses compostos, portanto, sua qualidade é um fator que deve ser atestado por meio de certificação. ${ }^{17}$

Todo cenário de incerteza em relação às certificações, vem aumentando significativamente o consumo de produtos orgânicos, que são vistos como uma excelente alternativa para evitar a ingestão de agrotóxicos na alimentação. A produção de alimentos orgânicos não possui em sua constituição a presença de insumos como pesticidas sintéticos, fertilizantes químicos e conservantes. Eles se destacam por sua baixa toxicidade, maior durabilidade e maior teor de alguns nutrientes em alguns alimentos, porém, mais estudos devem ser realizados para comprovar essa superioridade e afirmar se 
realmente existe vantagem em relação ao valor nutricional. ${ }^{18}$

O principal impedimento no consumo de alimentos orgânicos no país está ligado ao seu preço, devido a argumentos como: maior custo de produção, maior margem de lucros para produtos orgânicos, discriminação de preços e crescimento da demanda maior que o da oferta. Ou seja, o consumo de alimentos inorgânicos, na maioria das vezes não é por falta de informação, e sim falta de escolha ${ }^{19}$.

Existem testes capazes de avaliar a exposição à agentes mutagênicos e genotóxicos, sendo divididos em duas categorias: determinação dos níveis de agentes químicos e derivações em fluídos corporais, nas células, tecidos e nas excreções. ${ }^{20}$ Os métodos citogenéticos são utilizados in vitro e in vivo, possuem elevada sensibilidade e eficiência e são ideais para a detecção de efeitos genotóxicos, causados por substâncias prejudiciais ao DNA. ${ }^{21}$ Os ensaios que determinam a genotoxidade e mutagenicidade podem ser utilizados para detectar o risco de câncer associados aos agrotóxicos, porém, não dizem a respeito do potencial carcinogênico, afinal, o câncer é uma doença multifatorial. ${ }^{16}$

\subsection{Genotoxidade}

A genotoxidade está associada à capacidade de alguns agentes químicos ou físicos em danificar a informação genética no interior da célula, causando diversas enfermidades. Fatores físicos ou químicos agridem constantemente a molécula de DNA, e uma modificação em sua sequência pode desencadear uma alteração herdável da função gênica. ${ }^{14}$ A estabilidade do genoma é garantida pelos mecanismos de defesa constituídos nos sistemas de reparo do DNA, e sua compreensão é fundamental para identificar e entender como os agentes genotóxicos podem se tornar mutagênicos. Suas vias de reparo devem atuar em conjunto para que seja garantida a manutenção genética, e são basicamente classificadas em: reversão da lesão, reparo por excisão, reparo recombinacional e tolerância a lesões ${ }^{15}$

A maioria dos agentes mutagênicos possui uma relação de mutações característica, dependendo de vários fatores como: modificações de base, mudanças nos resíduos de açúcar ou fosfato, quebras de filamentos, ou incorporações de bases modificadas, e os subsequentes efeitos secundários, causados pela resposta do organismo a estas modificações. ${ }^{16}$ Os efeitos secundários podem incluir a ação de várias formas de reparo do 
material genético e a duplicação de filamentos filhos sobre moldes modificados. Os processos de mutagênese e carcinogênese (resultado de uma alteração irreversível no DNA) estão ligados por sua replicação e a proliferação celular. Os responsáveis por induzir este processo são por sua vez, os carcinógenos.

\subsection{Teste de exposição a agentes mutagênicos}

O teste micronúcleo $(\mathrm{MN})$ foi desenvolvido como uma opção mais simples para analisar os danos cromossômicos ${ }^{17}$. Os micronúcleos podem ser visualizados no citoplasma das células filhas, como pequenos corpos nucleares, em decorrência de danos induzidos às células parentais, revelando a ação de agentes clastogênicos, que quebram cromossomose aneugênicos, que induzem aneuploidia ou segregação cromossômica anormal. Diante disso, eles são utilizados como biomarcadores damutagenicidade em indivíduos exposto a agentes genotóxicos, pelo fato de ser considerado um procedimento rápido, simples, baixo custo, não invasivo e com alta sensibilidade. ${ }^{23}$

O teste $\mathrm{MN}$ é fundamental para a toxicologia genética e ambiental, pelo fato de detectar mutações cromossômicas, sendo considerado marcador precoce para carcinogênese. Tem sido utilizado em invertebrados, peixes e anfíbios como biomonitores de áreas contaminadas, e em ratos e camundongos sãoutilizados na triagem de compostos, para determinar a genotoxidade após a exposição direta ou indireta a diversos compostos. 24

O ensaio cometa, desenvolvido por Ostling e Johanson 1984 é modificado por Singh em 1988, é um teste utilizado para avaliar os danos genéticos (como quebra simples de genomas, quebras duplas e sítios lábeis alcalinos) causados pelo uso indiscriminado de agrotóxicos, e por sua vez, também é conhecido como eletroforese de célula única. O teste também é utilizado para avaliação de reparos do DNA. ${ }^{25}$

\section{CONSIDERAÇÕES FINAIS}

A partir da problemática do consumo de agrotóxicos pela população e seus danos à saúde, foi possível observar que os efeitos adversos na saúde dos indivíduos, incluindo os danos genéticos cometidos pelo uso de agrotóxicos, ainda é pouco conhecido e divulgado para a sociedade, o que reforça a importância de pesquisas que avaliem esses riscos e 
alertem aos órgãos responsáveis para monitorar a comercialização e uso desses agentes químicos, promovendo a segurança alimentar por meio de políticas de saúde.

As pesquisas envolvendo os danos genéticos ainda estão em evolução, estudos apontam que podem causar danos irreversíveis que podem ser passados às futuras gerações, o que torna o problema ainda maior, já que essas alterações genômicas geram impactos negativos à saúde. Diante desse cenário, nos deparamos com um problema político e econômico, capaz de criar um impasse entre a promoção da saúde e o constante uso de agrotóxicos com o objetivo de aumentar a produção agrícola.

\section{REFERÊNCIAS BIBLIOGRÁFICAS}

SPADOTTO, Claudio Aparecido. Abordagem interdisciplinar na avaliação ambiental de agrotóxicos. In: Embrapa Meio Ambiente-Artigo em anais de congresso (ALICE). In: JORNADA JURÍDICA DA FACULDADE MARECHAL RONDON, 4., 2006, São Manuel, SP. Artigos publicados... São Manuel, SP: FMR, 2006. p. I-9. Revista do Núcleo de Pesquisa Interdisciplinar, São Manuel, p. I-9, maio 2006.

SANTANA, Vilma Sousa; MOURA, Maria Claudia Peres; NOGUEIRA, Flávia Ferreira. Mortalidade por intoxicação ocupacional relacionada a agrotóxicos, 2000-2009, Brasil. Revista de Saúde Pública, v. 47, p. 598-606, 2013.

RIGOTTO, R. M; VASCONCELOS, D. P; ROCHA, M. M. Uso de agrotóxicos no Brasil e problemas para a saúde pública. Cadernos de Saúde Pública, v. 30, p. 1360-1362, 2014.

PIGNATI, W. A. et al .Distribuição espacial do uso de agrotóxicos no Brasil: uma ferramenta para a Vigilância em Saúde. Ciênc. saúde coletiva, Rio de Janeiro,v. 22, n. Io, p. 328I-3293, out. 2017 .

AGÊNCIA NACIONAL DE VIGILÂNCIA SANITÁRIA. Agrotóxicos em alimentos. 2020. Disponível em: <https://www.gov.br/anvisa/pt$\mathrm{br} /$ acessoainformacao/perguntasfrequentes/agrotoxicos/agrotoxicos-em-alimentos>. NUSSBAUM, R. L; MCINNES, R. R; WILLARD, H. F. Genética Médica. 8 ed. Rio de Janeiro: Elsevier, 2016. 532 p.

INSTITUTO NACIONAL DO CÂNCER (INCA). Posicionamento do Instituto Nacional do Câncer José Alencar Gomes da Silva acerca dos agrotóxicos. Disponível em: 
<https://www.inca.gov.br/sites/ufu.sti.inca.local/files//media/document//posicioname nto-do-inca-sobre-os-agrotoxicos-o6-abr-15.pdf $>$.

SALMÓRIA, Augusto César Faria. et al., Agrotóxicos: Benefícios e malefícios para a produção e sociedade. - análise dos dados do CEPON - centro de pesquisas oncológicas. 20r6. Trabalho de Conclusão do PIC-Química, Instituto Federal Catarinense, AraquariSC, 2016.

SILVA, Emanuelle Gonçalves. Agrotóxicos no Brasil: comparativo da atual legislação com o Projeto de Lei no 6.299/2002. 2019. 49 f. Monografia (Curso de Graduação em Direito) - Centro de Ciências Jurídicas e Sociais - CCJS/UFCG, 2019 SOUSA-PB.

AGÊNCIA NACIONAL DE VIGILÂNCIA SANITÁRIA. Programa de Análise de Resíduos de Agrotóxicos em Alimentos (PARA): Relatório das amostras analisadas no período de 2017-2018. ANVISA, Brasília, 2019. Disponível em:<https://www.gov.br/anvisa/pt-br/assuntos/agrotoxicos/programa-de-analise-deresiduos-em-alimentos/arquivos/377ojson-file-1>.

AGÊNCIA NACIONAL DE VIGILÂNCIA SANITÁRIA. Programa de Análise de Resíduos de Agrotóxicos em Alimentos (PARA): Relatório das Amostras Analisadas no Período 2013-2015. ANVISA, Brasília, 246 p., 2016. Disponível em: $<$ https://www.gov.br/anvisa/pt-br/assuntos/agrotoxicos/programa-de-analise-deresiduos-em-alimentos/arquivos/3778json-file-I>.

CARNEIRO et al. Dossiê ABRASCO: um alerta sobre os impactos dos agrotóxicos na saúde Rio de Janeiro: EPSJV: São Paulo: Expressão Popular; 2015.

ARIA, N.M.; FASSA, A.C.; FACCHINI, L.A. Intoxicação por agrotóxicos no Brasil: os sistemas oficiais de informação e desafios para realização de estudos epidemiológicos. 2007. Ciênc. Saúde

BAGATINI, M. D; SILVA, A. C. F; TEDESCO, S. B. Uso do sistema teste de Allium cepa como bioindicador de genotoxicidade de infusões de plantas medicinais. Revista Brasileira de Farmacognosia, v. 17, n. 3, p. 444-447, 2007.

BERRA, C. M; MENCK, C. F. M; DI MASCIO, P. Estresse oxidativo, lesões no genoma e processos de sinalização no controle do ciclo celular. Química Nova, v. 29, n. 6, p. 1340, 2006. 
CARVALHO, Wanessa Fernandes. Avaliação de danos genéticos e correlação com polimorfismo nos genes gstml e gsttl em trabalhadores ocupacionalmente expostos a agrotóxicos em municípios goianos com intensa atividade agrícola. 2014. $88 \mathrm{f}$. Dissertação (Mestrado em genética) Universidade Católica de Goiás, Goiânia, 20r4.

SILVA, Elisangela de Jesus. Avaliação dos efeitos genotóxicos de agrotóxicos: Risco ocupacional e alimentar. 2012. 53 f. Dissertação (Mestrado em saúde humana e meio ambiente) Universidade Federeal de Pernambuco, Pernambuco : Vitoria de santo antão, 2012.

BORGUINI, R. G; TORRES, E. A. F. S. Alimentos orgânicos: qualidade nutritiva e segurança do alimento. Segurança alimentar e Nutricional, v. 13, n. 2, p. 64-75, 2006.

SOUSA, A. A. et al. Alimentos orgânicos e saúde humana: estudo sobre as controvérsias. Revista Panamericana de Salud Pública, v. 31, p. 513-517, 2012.

GRISOLIA, Cesar Koppe. Agrotóxicos: mutações, reprodução \& câncer; riscos ao homem e ao meio ambiente, pela avaliação de genotoxicidade, carcinogenicidade e efeitos sobre a reprodução . Ed. $U$ nB, 2005 .

BELPAEME, K. et al. Estudos citogenéticos de $\mathrm{PCB}_{77}$ em truta marrom (Salmo truttafario) usando o teste do micronúcleo e o ensaio do cometa alcalino. Mutagenesis, v. II, n. 5, pág. 485-492, 1996.

SCHMID, W. The micronucleus test for cytogenetic analysis. In: Mutagênicos químicos . Springer, Boston, MA, 1976. p. 31-53.

SILVA, Hugo Gama Aguiar. Avaliação genotóxica dos pesticidas metomil e cipermetrina: efeitos agudos in vivo. 2013. 23 f. Dissertação de Mestrado. Universidade Federal de Pernambuco, Pernambuco, 2013.

BONASSI, S. et al. Frequência de micronúcleos em linfócitos de sangue periférico e risco de câncer: evidências de estudos em humanos. Mutagenesis , v. 26, n. I, pág. 93-100, 201 I. UMBUZEIRO, G. A. et al. Avaliação da genotoxicidade da água do Estuário de Santos (Brasil) em relação à contaminação de sedimentos e lançamento de efluentes. Meio Ambiente internacional, v. 32, n. 3, pág. 359-364, 2006. 